\title{
ESCOLHA DO USO DO VALOR JUSTO PARA PROPRIEDADES PARA INVESTIMENTOS: UMA INFLUÊNCIA DAS CARACTERÍSTICAS DE EMPRESAS LISTADAS NA BM\&FBOVESPA E NA NYSE
}

Reiner Alves Botinha ${ }^{1}$

Sirlei Lemes ${ }^{2}$

Resumo: A pesquisa objetivou identificar as possíveis explicações para as escolhas contábeis realizadas por gestores de companhias abertas listadas na NYSE e na BM\&FBOVESPA, com relação à mensuração subsequente de Propriedades para Investimentos referente ao ano de 2013. As hipóteses levantadas atinentes aos incentivos das decisões dos gestores foram embasadas na Teoria da Agência e na abordagem metodológica empírico positivista, pressupondo que as escolhas contábeis podem ser explicadas por meio da relação entre as características das empresas e os interesses dos gestores. $O$ presente estudo identificou que, de uma forma mais conservadora, para ambas as bolsas, ocorreu maior utilização do método do custo pelas empresas da amostra. Na comparação entre as empresas listadas na BM\&FBOVESPA e na NYSE, as variáveis Big Four, tamanho da empresa, relevância do saldo de PPI e o fato de a empresa pertencer ao setor de telecomunicações, apresentaram-se como variáveis explicativas para a decisão sobre o método contábil a ser empregado. Embora não tenha sido encontrada influência de planos de incentivos nas escolhas contábeis realizadas pelas empresas amostrais, verificou-se que, havendo discricionariedade no tratamento contábil, existem características que podem definir a escolha pelo uso do valor justo.

Palavras-chave: Escolhas Contábeis. Propriedades para Investimento. Teoria da Agência. Abordagem metodológica empírico positivista. 


\section{SELECT THE USE OF FAIR VALUE FOR PROPERTY INVESTMENT: AN INFLUENCE OF THE CHARACTERISTICS OF CMPANIES LISTED ON THE BM\&FBOVESPA AND THE} NYSE

Abstract: The research aimed to identify possible explanations for the accounting choices made by managers of public companies listed on the NYSE and the BM\&FBOVESPA, in relation to subsequent measurement of investment properties for the year 2013. The hypotheses regarding the incentives of managers' decisions were based on the Agency Theory and empirical-positivist methodological approach, assuming that the accounting choices can be explained by the relation between the characteristics of the companies and the interests of managers. The present study identified that, in a more conservative way, for both stock markets, there was increased use of the cost method by the companies in the sample. In a comparison among companies listed on the BM\&FBOVESPA and the NYSE, the variables Big Four, size of company, relevance of PPI amount, and the companies'appertaining to the telecommunications industry, presented to be explanatory variables for the decision of the accounting method to be employed. Although it wasn't found influence of incentive plans on accounting choices made by companies of the sample, it was found that in the presence of discretion in accounting treatment, there are characteristics that can define the use of fair value option.

Keywords: Accounting Choices. Investment Properties. Agency Theory. Empirical-positivist methodological approach. 


\section{INTRODUÇÃO}

A dmitindo-se a abordagem metodológica empírico positivista embasada na Teoria da Agência, que pondera que os indivíduos agem de acordo com seus interesses pessoais, para diferentes tratamentos contábeis admitem-se hipóteses oportunísticas que asseveram que as características das empresas podem se comportar como incentivos para as escolhas contábeis (Watts \& Zimmerman, 1986).

As International Financial Reporting Standards (IFRS) trouxeram, como um de seus fundamentos, o estímulo ao julgamento profissional por meio da presença das escolhas contábeis. Segundo Watts (1992), tais escolhas nada mais são do que opções dos gestores por um método contábil em detrimento de outro, permitindo-se, assim, o "olhar do gestor" para a transação e a sua decisão quanto ao melhor tratamento contábil que seja adequado à substância econômica dessa transação, atendendo, assim, às características qualitativas fundamentais da relevância e da representação fidedigna.

Outrossim, esse ponto viceja discussão e, segundo Bayerlein e Al Farooque (2012), qualquer forma de normatização de práticas contábeis que aumente o número de opções disponíveis de tratamentos contábeis ou a quantidade de julgamento profissional requerida pode ter um efeito negativo na convergência na prática, resultando em diferentes formas de reconhecimento, mensuração e divulgação para um mesmo evento econômico. Assim, enquanto as escolhas contábeis parecem possibilitar uma representação contábil mais fiel à substância econômica dos eventos, por outro lado, podem gerar relatórios contábeis não comparáveis.

Sobreleva notar que o espaço propiciado pelas normas para as escolhas contábeis, justifica-se pela busca em se atender a diversos fatores como diferentes tipos de negócios, diferenças entre países, e outros de influência como os incentivos contratuais e o fato de os administradores possuírem remunerações variáveis (Cole, Branson \& Breesch, 2011). Cumpre, portanto, à pesquisa em contabilidade, por meio da identificação de possíveis incentivos dos gestores, identificar se tais incentivos são capazes de explicar e predizer as escolhas contábeis (Watts \& Zimmerman, 1986; Lopes, 2012).

No âmbito das críticas ao modelo IFRS, discussões quanto aos entraves não se limitam à presença das escolhas contábeis no corpo textual das normas. Segundo Muller, Riedl e Sellhorn (2008), "as IFRS têm sido criticadas tanto pela flexibilidade permitida nas normas, quanto pela inserção do paradigma do valor justo" (p. 3).

Quando se trata do paradigma do valor justo, levanta-se uma mudança de capital importância, no que diz respeito à forma de mensuração dos itens das demonstrações financeiras. Analisando o elemento "Propriedades para Investimento (PPI)" de duas empresas, o fato de as circunstâncias terem levado o gestor de uma delas a mensurar o item ao valor justo e o gestor da outra empresa a mensurar item similar ao valor de custo histórico pode tornar as duas contas não comparáveis, mesmo sendo itens semelhantes.

Logo, uma das escolhas contábeis propiciada pelas IFRS é a possibilidade de mensuração das PPI após o reconhecimento inicial, ao valor justo. Dessa forma, este item é elencado para a presente pesquisa, por propiciar analisar, consecutivamente, o efeito da flexibilidade proporcionada com as escolhas contábeis e da adoção específica do método do valor justo, salientado por Muller et al. (2008). 
Assim, este estudo ocupa-se em responder à seguinte questão: quais são as características que motivam as escolhas contábeis dos gestores de companhias abertas listadas na NYSE e companhias listadas na BM\&FBOVESPA, em relação à mensuração subsequente de PPI?

Cairns, Massoudi, Taplin e Tarca (2011) identificaram, com uma amostra de 228 companhias abertas (114 da Austrália e 114 do Reino Unido), uma forte adesão ao valor justo na mensuração subsequente das PPI. Usando períodos e abordagens distintos, algumas pesquisas apontaram maior registro de PPI ao custo histórico pelas empresas brasileiras (Andrade, Silva \& Malaquias, 2013; Batista, Prado, Machado \& Paulo, 2013; Costa, Silva \& Laurencel, 2013; Freri \& Salotti, 2013; Pereira, 2013). Instou-se, portanto, esclarecer tais diferenças perante os mercados de capitais.

Comparou-se, por conseguinte, empresas listadas na NYSE e BM\&FBOVESPA, fazendo uma alusão ao impacto da diferença entre mercado de capitais em termos de grau de desenvolvimento, além de permitir uma amostra diversificada em sua nacionalidade, uma vez que se selecionaram empresas originadas de quinze países diferentes. Pereira (2013) infere, perante a pouca adesão de empresas brasileiras, a mensuração ao valor justo, em que quanto mais desenvolvido é o mercado de capitais na qual a empresa é listada, maior será sua acessibilidade e aceitabilidade ao valor justo. Cumpre destacar que a NYSE é a bolsa de valores com maior valor de transações eletrônicas negociadas e maior capitalização de mercado acionário doméstico no final de 2013 (World Federation of Exchanges [WFE], 2014).

Alicerçada na Teoria da Agência e na abordagem metodológica empírico positivista, a pesquisa foi conduzida partindo do pressuposto de que as escolhas contábeis podem ser explicadas com base no alinhamento entre as características das empresas e os interesses dos indivíduos que ocupam a gestão dessas empresas (alinhamento que se constitui em um conjunto de relações contratuais entre as partes). As características das empresas analisadas, como explicativas para as escolhas contábeis, foram: rentabilidade, grau de endividamento, tamanho da empresa, assimetria informacional, empresa de auditoria, setor, bolsas de valores e relevância do saldo da conta de PPI.

Nessa perspectiva, o diferencial percebido na pesquisa consiste em: (i) ter por amostragem empresas de quinze países analisados com uma parcela representativa do PIB mundial; (ii) identificar se as empresas com PPI têm aderido ao método de mensuração ao valor justo, após o reconhecimento inicial; e (iii) identificar as características que possam fornecer explicações para as escolhas contábeis. Além dessas contribuições, espera-se que a pesquisa atenda à necessidade latente de mais investigações sobre o tema escolhas contábeis, em razão da importância adquirida com a adoção das IFRS.

\section{REFERENCIAL TEÓRICO}

\subsection{PROPRIEDADES PARA INVESTIMENTOS: CRITÉRIOS NORMATIVOS E DE MENSURAÇÃO}

Desde 2001, mais de 130 países (International Financial Reporting Standards Foundation [IFRS Foundation], 2014) têm vivenciado o processo de convergência às IFRS, aceitas por boa parte do mercado de capital internacional. Carvalho, Lemes e Costa (2006) ressaltam que as IFRS permitem aos usuários a comparação entre diversos investimentos em diferentes países, dando-Ihes subsídios para suas escolhas quanto aos melhores investimentos. Desse modo, a simples adesão dos países às IFRS não se traduz, necessariamente, na convergência contábil: é preciso que o escopo das normas garanta aos usuários uma melhor tomada de decisões e comparabilidade.

A Propriedade para Investimento, foco da International Accounting Standard 40 (IAS 40, Investments Property), pode ser definida como "propriedades (terreno ou um edifício, ou parte de um edifício, ou 
ambos) mantidas (pelo dono ou locatário em um leasing financeiro) para se obter renda, valorização de capital ou para ambos", não incluindo propriedades usadas para fins de produção, comercialização e/ou venda, ou para o funcionamento administrativo (International Accounting Standard 40 [IAS 40], 2013, item 5).

A mensuração das PPI deve ocorrer, inicialmente, pelo custo, incluídos os custos de transação (IAS 40,2013 , item 20). Quanto à mensuração após o reconhecimento inicial, a norma permite a escolha entre o modelo de valor justo (método de avaliação de ativo a valor de saída) e o modelo de custo depreciado (menos quaisquer perdas acumuladas por redução ao valor recuperável, como um método de avaliação de ativo a valor de entrada), sendo que, para as entidades que optarem pelo modelo de custo, deve-se divulgar o valor justo das PPI em notas explicativas (IAS 40, 2013, item 79).

A opção deve ser feita pela entidade que reporta a informação, porém prezando pela consistência ao longo dos períodos (IAS 40, 2013; Martins, Gelbcke, Santos \& ludícibus, 2013), ou seja, uma vez mensurado ao valor justo, é aconselhável a mudança de um método para outro, apenas se a alteração resultar em uma apresentação mais relevante (IAS 40, 2013, item IN17). No entanto, torna-se improvável que a mudança ocorra do método do valor justo para o método de custo, pois dificilmente resultará em uma apresentação mais relevante. Outro ponto importante é que, se a empresa optar pelo custo depreciado, deve divulgar o valor justo da propriedade em notas explicativas (IAS 40, 2013, item IN12).

Assim, parece haver uma preferência, por parte dos órgãos reguladores, pela mensuração subsequente ao valor justo, pois, seja no valor reconhecido da PPI ou apenas na divulgação em notas explicativas, as entidades deverão proceder a esse método de mensuração (IAS 40, 2013, item 32; Taplin, Yuan \& Brown, 2014).

Levantou-se, inicialmente, a possibilidade de remover a escolha contábil e orientar os profissionais quanto ao melhor modelo que deveria ser seguido (Basis for Conclusions, IAS 40, 2013, item BC11). Contudo, eles identificaram que a discricionariedade incluída na norma se dava por dois motivos: o primeiro é que se permitia, naquele instante, aos elaboradores das demonstrações contábeis, mais tempo para se familiarizarem e experienciarem com o uso e entendimento do valor justo; e o segundo foi para permitir aos países com mercados imobiliários menos desenvolvidos mais tempo para amadurecerem o grupo de profissionais da área para aderirem ao método do valor justo (Basis for Conclusions, IAS 40, 2013, item BC12). Assim, coube, no presente estudo, identificar a adesão do método de mensuração, bem como buscar na literatura teorias que apontassem possíveis variáveis que pudessem explicá-lo.

\subsection{ABORDAGEM METODOLÓGICA EMPÍRICO POSITIVISTA E A TEORIA DA AGÊNCIA}

Verifica-se, por meio da literatura, que o desenvolvimento da abordagem metodológica empírico positivista e as possíveis explicações para as escolhas contábeis (inclusive as hipóteses oportunísticas) se alicerçam em teorias econômicas, sendo utilizada como base no presente estudo a Teoria da Agência (Agency Theory). Apoiada nos princípios dessa teoria econômica, parte-se do pressuposto de que os indivíduos agem na medida de seus interesses pessoais, maximizando seu bem-estar (Lopes, 2012).

Taplin et al. (2014) avaliam a Teoria da Agência como uma construção importante para a abordagem empírico positivista, que, diante do princípio que fundamenta a teoria da agência, impende ao entendimento das práticas de comunicação corporativa (por meio das demonstrações financeiras), fornecendo explicações para as escolhas dos métodos contábeis por parte dos gestores, diante do trade-off (situação em que há conflito de escolha) entre os vários possíveis incentivos. Os autores acrescentam que 
a Teoria da Agência é "uma estrutura conceitual popular para pesquisadores interessados em temas como conflitos de interesse, questões de escolha contábil, problemas de incentivos e mecanismos para gerenciá-los" (Taplin et al., 2014, p. 5).

Um dos estudos seminais baseados na abordagem metodológica empírico positivista foi o estudo de Watts e Zimmerman (1986), que, entre suas contribuições, buscando explicações e predições na prática contábil, levantaram três hipóteses: (a) a hipótese do plano de incentivo (the bonus plan hypothesis); (b) a hipótese do grau de endividamento (the debt covenant hypothesis); e (c) a hipótese do tamanho ou dos custos políticos (the political cost hypothesis).

Na hipótese do plano de incentivo (Watts \& Zimmerman, 1986), os administradores que recebem remuneração e resultados variáveis tenderão a buscar tratamentos contábeis que aumentem os resultados do período, incrementando também o valor das remunerações e bônus (Jensen \& Meckling, 1976; Watts \& Zimmerman, 1986; Fields, Lys \& Vincent, 2001; Lopes, 2012).

Na hipótese do grau de endividamento (Watts \& Zimmerman, 1986), as empresas que enfrentam maior grau de endividamento tendem a recorrer a métodos que aumentem o lucro, sendo que quanto mais endividada, mais restrita a empresa se encontra para captar investimentos e outras ações, incorrendo em riscos de insolvência (Jensen \& Meckling, 1976; Watts \& Zimmerman, 1986; DeAngelo, DeAngelo \& Skinner, 1994; Fields et al., 2001; Lopes, 2012).

A hipótese dos custos políticos (Watts \& Zimmerman, 1986), por sua vez, versa que as empresas maiores tenderão a adotar procedimentos contábeis com vistas a reduzir os lucros para diminuir os seus custos políticos, haja vista que, quanto maior o porte da empresa, maior é a atenção por parte do governo e da sociedade, forçando a empresa a adotar atitudes mais conservadoras (Jensen \& Meckling, 1976; Watts \& Zimmerman, 1986; Fields et al., 2001; Lopes, 2012). Estudos anteriores testaram tais hipóteses e são destacados no Quadro 1.

Quadro 1: Estudos anteriores

\begin{tabular}{|c|c|c|c|}
\hline Andrade et al. (2013) & $\begin{array}{c}\text { Hipótese do plano de } \\
\text { incentivo }\end{array}$ & $\begin{array}{c}\text { Hipótese do grau de } \\
\text { endividamento }\end{array}$ & $\begin{array}{c}\text { Hipótese dos custos } \\
\text { políticos }\end{array}$ \\
\hline $\begin{array}{c}\text { significativa da utilização } \\
\text { de escolhas contábeis para } \\
\text { gerenciar resultados. }\end{array}$ & $\begin{array}{c}\text { Não se identificou relação } \\
\text { entre a opção pelo valor } \\
\text { justo e a alavancagem. }\end{array}$ & $\begin{array}{c}\text { A variável tamanho da } \\
\text { empresa não influenciou } \\
\text { a escolha contábil pelo } \\
\text { valor justo. }\end{array}$ \\
\hline $\begin{array}{c}\text { Christensen e Nikolaev } \\
\text { (2013) }\end{array}$ & $\begin{array}{c}\text { Não foram utilizadas proxies } \\
\text { referentes a esta hipótese. }\end{array}$ & $\begin{array}{c}\text { A decisão de utilizar } \\
\text { o valor justo nas PPI } \\
\text { está relacionada } \\
\text { positivamente com o } \\
\text { endividamento. }\end{array}$ & $\begin{array}{c}\text { A probabilidade de usar } \\
\text { o valor justo aumenta } \\
\text { com a proporção de PPI } \\
\text { em relação aos ativos } \\
\text { totais. }\end{array}$ \\
\hline Costa et al. (2013) & $\begin{array}{c}\text { A variável rentabilidade não } \\
\text { apresentou significância } \\
\text { estatistica. }\end{array}$ & $\begin{array}{c}\text { A variável endividamento } \\
\text { não apresentou } \\
\text { significância estatística. }\end{array}$ & $\begin{array}{c}\text { As empresas que } \\
\text { adotam o método do } \\
\text { custo são maiores (ativo } \\
\text { total e receita líquida) } \\
\text { do que as empresas que } \\
\text { usam valor justo. }\end{array}$ \\
\hline Taplin et al. (2014) & $\begin{array}{c}\text { Empresas chinesas com } \\
\text { maior volatilidade nos lucros } \\
\text { divulgados tendem a optar } \\
\text { pelo valor justo. }\end{array}$ & $\begin{array}{c}\text { A variável grau de } \\
\text { alavancagem não } \\
\text { apresentou significância } \\
\text { estatística. }\end{array}$ & $\begin{array}{c}\text { Empresas chinesas } \\
\text { menores tendem a optar } \\
\text { pelo método do valor } \\
\text { justo. }\end{array}$ \\
\hline
\end{tabular}

Em linha com os estudos citados, a presente pesquisa buscou identificar possíveis explicações para as opções das empresas na mensuração das PPI.

\subsection{ESCOLHAS CONTÁBEIS}

De acordo com Jaafar \& McLeay (2007, p. 157), “a diversidade da contabilidade é o resultado natural de variadas circunstâncias de negócios, que, por necessidade, podem exigir diferentes tratamentos con- 
tábeis". Entende-se que a discricionariedade propiciada nas normas se fundamentou no atendimento a tal variedade, embora, como exposto, as escolhas possam não ser feitas apenas por uma exigência das circunstâncias dos negócios das entidades, mas também por diversos incentivos.

Indaga-se, portanto, o motivo para a permanência das escolhas permitidas nas normas, diante da existência de incentivos. Apesar da existência de tais permissões, a estrutura conceitual das IFRS estabelece como objetivo das características qualitativas "fornecer uma base para a redução do número de tratamentos contábeis alternativos permitidos pelas IFRS" (Framework, 2013, item "Purpose and status"). "O IASB reconsiderou e continuará a reconsiderar as transações e os eventos para os quais as IFRS permitem uma escolha contábil, com o objetivo de reduzir o número dessas escolhas" (Preface to IFRS, 2013). Logo, fica expresso que o IFRS Foundation, ainda como IASB (International Accounting Standard Board), já havia se posicionado sobre a redução das escolhas contábeis.

Oportuno se torna destacar que a permissão para as escolhas não são, aparentemente, inserções e objetivos arbitrários ou sem fundamento. Em 1989, no Exposure Draft 32, o IASB já tinha o tema em sua agenda, como pode ser percebido pela proposta de "melhorar a comparabilidade internacional das demonstrações financeiras, reduzindo substancialmente o leque de opções contidas em normas do IASC" (Thorell \& Whittington, 1994, p. 222).

A ideia desse projeto surgiu da necessidade do IOSCO (The International Organization of Securities Commissions) de fomentar o número de empresas com ações negociadas em mercados estrangeiros. $O$ mesmo órgão acentuou que as normas internacionais, até então elaboradas, continham muitas escolhas contábeis para serem aceitáveis pelos mercados, e que, se tais escolhas fossem reduzidas, aumentariam as chances de aceite e adoção pelas em bolsas (Roberts, Salter \& Kantor, 1996).

Há quem defenda que, sem regras rígidas, normas baseadas em princípios permitiriam maior flexibilidade, o que resultaria em fraude contábil. No entanto Carmona e Trombetta (2008) mencionam que essa abertura e flexibilidade, apesar de gerar possíveis problemas relacionados à comparabilidade das informações contábeis e da forma que são mensuradas, alegam, em sua pesquisa, que a flexibilidade poderia proporcionar um impedimento à fraude. Nesse mesmo contexto, Barth (2008) cita que normas baseadas em princípios, não necessariamente, são menos rigorosas que as normas baseadas em regras, ao contrário, a autora postula que os princípios são mais difíceis de proporcionar gerenciamento de resultados.

Segundo Fields et al. (2001), ante as escolhas contábeis permitidas pelas normas, gerentes cujos incentivos são consistentes com os dos proprietários das empresas podem fazer uma escolha contábil para transmitir informação privada para os investidores, enquanto outros gestores podem usar do senso oportunista para, por exemplo, inflar os lucros, a fim de aumentar sua remuneração. Isso se configuraria como gerenciamento de resultados. Entretanto, para Fields et al. (2001), cabe frisar, não são todas as escolhas contábeis que levam ao gerenciamento de resultados.

Para os mesmos autores, a melhor saída não seria, portanto, criar regras para todos os fatos e circunstâncias, uma vez que, em um cenário em que novas normas contábeis estão sendo criadas ou revisadas constantemente, torna-se improvável eliminar as escolhas contábeis. Os autores explicam que a escolha é parte de uma solução ótima para o problema de agência e que, quando o sistema não prevê julgamentos, informações úteis podem ser perdidas (Fields et al., 2001).

Pode haver outra justificativa possível para as escolhas contábeis: o status quo. Status quo, (Messier, Quick e Vandervelde, 2014), é quando se decide manter a decisão anterior ou atual, não optando por uma mudança, o que se constitui em uma heurística cognitiva, que, segundo Tonetto, Kalil, Melo, 
Schneider \& Stein (2006), são "regras gerais de influência utilizadas pelo decisor para simplificar seus julgamentos em tarefas decisórias de incerteza" (p. 181).

Muitos dos julgamentos e decisões são tomados sob incerteza e desconhecimento quanto às previsões dos resultados das decisões (Tonetto et al., 2006). Nesse caso, em razão da resistência à mudança por parte de profissionais contábeis, percebe-se a manutenção do uso do método do custo, pois a mudança de tratamento causa um rompimento de paradigma e, assim, os preparadores são tentados a continuar usando o tratamento anterior (Demaria \& Dufour, 2007). Lourenço e Curto (2010), a respeito dos determinantes da escolha contábil, reforçam tal ideia ao afirmarem que o gestor deixaria de migrar para um novo tratamento contábil, para evitar custos e riscos, bem como sair de sua "zona de conforto".

\section{ASPECTOS METODOLÓGICOS}

\subsection{COLETA DE DADOS E AMOSTRA DA PESQUISA}

Para responder ao problema de pesquisa, incluindo o teste das hipóteses, foi elencado um conjunto de dados provenientes das empresas listadas na BM\&FBOVESPA e na NYSE, do ano de 2013.

A limitação do uso de apenas um período ocorreu em virtude da tentativa de se obter, estatisticamente, um maior poder explicativo, utilizando um número significativo de empresa que já se apresentou reduzida em virtude de muitas empresas não reconhecerem $\mathrm{PPI}$, sobretudo no que se refere à amostra de empresas listadas na NYSE. Inicialmente, foi executado um teste, analisando-se um período de 2009 a 2013. No entanto, a listagem de empresas arroladas na NYSE, que reconheciam PPI ao longo dos cinco anos consecutivos, reduziu-se para apenas dezoito empresas.

Entende-se, também, que as entidades não oscilariam sua opção ao longo dos anos, uma vez que elas devem prezar pela consistência ao longo dos períodos, além de ser notada a utilização de um único período em importantes pesquisas correlatas (Tudor \& Dragu, 2010; Cairns et al., 2011; Taplin et al., 2014). No Quadro 2, são apresentados os critérios empregados para a definição da amostra da pesquisa.

Quadro 2: Seleção da amostra de empresas listadas na BM\&FBOVESPA e NYSE

\begin{tabular}{|c|c|c|}
\hline ETAPAS DE SELEÇÃO DAS EMPRESAS & BM\&F & NYSE \\
\hline Número de empresas listadas na respectiva bolsa de valores em jun./14 & 523 & 520 \\
\hline (-) № de empresas excluídas por serem controladas por outras já selecionadas & $(16)$ & (99) \\
\hline (-) Empresas excluídas por não ter disponibilizado o relatório de 2013 & - & (14) \\
\hline $\begin{array}{l}\text { (-) No de empresas excluídas por não publicarem as demonstrações financeiras em conformidade com } \\
\qquad \text { as IFRS }\end{array}$ & - & (184) \\
\hline (-) № de empresas excluídas por não apresentarem saldo de PPI & (451) & (177) \\
\hline $\begin{array}{l}\text { (-) No de empresas listadas na NYSE excluídas por serem controladas por empresas já listadas na amostra } \\
\text { da BM\&FBOVESPA }\end{array}$ & - & (3) \\
\hline (-) № de empresas excluídas por estarem listadas em setores que não constam na outra amostra & (2) & $(2)$ \\
\hline (-) № de empresas excluídas por não disporem de informações necessárias para a análise no Capital IQ & (7) & $(0)$ \\
\hline Total de empresas da amostra & 47 & 41 \\
\hline
\end{tabular}

Para as empresas listadas na BM\&FBOVESPA, as respectivas demonstrações financeiras foram obtidas por meio do sítio eletrônico da CVM. Para as empresas listadas na NYSE, as respectivas demonstrações financeiras foram obtidas por meio do sítio eletrônico da SEC, garantindo a padronização e confiabilidade na coleta de dados em uma mesma base, considerando que a amostra era composta de empresas de quinze países. 
Ressalta-se que nem todos os países das empresas que compuseram a amostra adotaram localmente as IFRS, mas, para a seleção das empresas, elencaram-se aquelas que optaram por arquivar os relatórios contábeis em IFRS na SEC, sendo certificado o parecer de auditoria manifestando conformidade com as IFRS. Dessa forma, não foram analisados na pesquisa relatórios sob os princípios contábeis, geralmente, aceitos dos países (General Accepted Accounting Principles - GAAP), uma vez que a SEC, em 2007, passou a permitir que empresas estrangeiras arquivassem os relatórios em IFRS sem necessidade de reconciliação para US GAAP (em conformidade com as normas do Financial Accounting Standards Board - FASB).

No que se refere ao foco em PPI, intencionou-se analisá-lo, por permitir escolhas claras (baseado no estudo e classificação de Cole et al., 2011). As escolhas contábeis claras são aquelas que possibilitam tratamentos contábeis alternativos para um mesmo evento, possibilitando, de fato, uma livre escolha ao gestor para tomar a decisão (por exemplo, ao inventariar o estoque usando PEPS ou Média Ponderada, não impondo, inicialmente, nenhuma obrigatoriedade quanto a algum dos métodos) (Cole et al., 2011). Com uma terminologia similar, Pinto, Martins e Silva (2015) chamam-na como escolha contábil "explícita".

A partir dos relatórios contábeis e notas explicativas coletados, foram extraídos os seguintes dados: a escolha contábil, o saldo da conta PPI, a presença de divulgação do valor justo das PPI para as empresas que optaram pelo custo histórico e a empresa de auditoria responsável. As demais variáveis alusivas às características das empresas foram coletadas por meio do banco de dados Capital IQ ${ }^{\circledR}$ desenvolvido pela Standard \& Poors ${ }^{\circledR}$.

Torna-se importante esclarecer que sete empresas listadas na BM\&FBOVESPA foram excluídas da amostra por não estarem na base Capital $I Q^{\circledR}$, e, consequentemente, não disporem de informações para a análise quantitativa dos dados, optando-se, também, por não proceder à coleta manual para não incorrer em viés de informações por fontes diversas de coleta de dados para uma mesma variável.

\subsection{DESENHO DA PESQUISA E VARIÁVEIS EXPLICATIVAS UTILIZADAS}

A partir da plataforma teórica e de estudos anteriores, fez-se um levantamento das características das empresas que podem ser testadas como fatores explicativos para as escolhas contábeis realizadas, sendo elas: rentabilidade, grau de endividamento, tamanho da empresa, assimetria informacional, proporção do saldo de PPI, empresa de auditoria, setor de atuação de negócios e bolsa de ações listada, conforme Quadro 3.

Quadro 3: Formulação das hipóteses

\begin{tabular}{|c|c|c|}
\hline Hipótese & Estudos anteriores & Expectativa e variável utilizada \\
\hline $\begin{array}{l}\text { H1: Empresas com alto nível } \\
\text { de rentabilidade (ROE) são } \\
\text { mais propensas ao uso } \\
\text { do método do valor justo } \\
\text { para PPI. }\end{array}$ & $\begin{array}{c}\text {-Devido aos índices de rentabilidade serem empregados como } \\
\text { medida de desempenho das empresas e os gestores saberem que } \\
\text { os stakeholders possuem expectativas sobre esse desempenho, } \\
\text { os gestores tendem a ser incentivados a escolher métodos que } \\
\text { contribuam para alcançar esse desempenho (Costa et al., 2013) } \\
\text {-Empresas com necessidade de financiamento focam no aumento dos } \\
\text { indicadores e na indução do mercado, optando, então, pelo método } \\
\text { do valor justo (Pereira, 2013). } \\
\text { - A opção pelo método de mensuração a valor justo aumenta o valor } \\
\text { do ativo, do resultado do exercício e, consequentemente, o valor do } \\
\text { patrimônio líquido da entidade (Costa et al., 2013). }\end{array}$ & $\begin{array}{l}\text { Espera-se que a empresa opte pelo método } \\
\text { que aumente o lucro da empresa, ou seja, o } \\
\text { valor justo (sinal positivo). } \\
\text { Variável explicativa utilizada: Retorno sobre } \\
\text { o Patrimônio Líquido (ROE), coletado por } \\
\text { meio do Capital IQ, originado da relação } \\
\text { entre o lucro operacional líquido ajustado e o } \\
\text { patrimônio líquido médio. }\end{array}$ \\
\hline $\begin{array}{l}\text { H2: Empresas com maior } \\
\text { grau de endividamento } \\
\text { são mais propensas ao uso } \\
\text { do método do valor justo } \\
\text { para PPI. }\end{array}$ & $\begin{array}{c}\text {-As escolhas refletem mais as dificuldades financeiras das empresas } \\
\text { do que tentativas de violar contratos e mascarar dívidas (DeAngelo } \\
\text { et al., 1994). } \\
\text {-É inconsistente a conclusão de que as empresas valem-se do } \\
\text { valor justo de forma oportunista para evitar violações de dívidas } \\
\text { (Christensen \& Nikolaev, 2013). } \\
\text {-A variável endividamento não influencia a escolha contábil (Andrade } \\
\text { et al., 2013; Taplin et al., 2014). }\end{array}$ & $\begin{array}{l}\text { Espera-se que quanto maior for o quociente } \\
\text { entre capital de terceiros e capital } \\
\text { próprio, maior a tendência para que os } \\
\text { administradores optem pelo método contábil } \\
\text { que proporcione maior lucro (sinal positivo). } \\
\\
\text { Variável explicativa utilizada: Quociente entre } \\
\text { capital de terceiros e capital próprio. }\end{array}$ \\
\hline
\end{tabular}




\begin{tabular}{|c|c|c|}
\hline $\begin{array}{l}\text { H3: Empresas maiores são } \\
\text { menos propensas ao uso do } \\
\text { valor justo para PPI. }\end{array}$ & $\begin{array}{l}\text {-As empresas tendem a selecionar métodos contábeis mirando reduzir } \\
\text { ou até adiar os impostos e evitar potencial fiscalização (Fields et al., } \\
\qquad \text { 2001). } \\
\text {-Quanto maior o tamanho da empresa, menos propensa ela é a adotar } \\
\text { o método do valor justo (Costa et al., 2013; Taplin et al., 2014). } \\
\text {-As pequenas empresas possuem maior risco econômico do que as } \\
\text { grandes, pois seus retornos são mais voláteis, tendendo a adotar um } \\
\text { método mais conservador, evitando adicionar volatilidade contábil à } \\
\text { volatilidade econômica (Demaria \& Dufour, 2007). }\end{array}$ & $\begin{array}{l}\text { Espera-se que quanto maior o porte da } \\
\text { empresa (medido pelo saldo do ativo total), } \\
\text { maior a visibilidade política e maior é a } \\
\text { probabilidade de optar por procedimentos } \\
\text { que reduzam o lucro (adotando o método } \\
\text { do custo), reduzindo a incidência de carga } \\
\text { tributária e/ou de maior monitoramento (sinal } \\
\text { positivo). } \\
\text { Variável explicativa utilizada: Quociente entre } \\
\text { capital de terceiros e capital próprio. }\end{array}$ \\
\hline $\begin{array}{l}\text { H4: Empresas com menores } \\
\text { bid-ask spread são mais } \\
\text { propensas ao uso do valor } \\
\text { justo para PPI. }\end{array}$ & $\begin{array}{l}\text {-A assimetria informacional consiste no "quanto de informação a } \\
\text { contabilidade não conseguiu passar ao mercado" (Martins, Pinto \& } \\
\text { Alcoforado, 2012, p. 3). } \\
\text {-Empresas com maior assimetria e menor bid-ask spread de } \\
\text { informação de informação (diferença entre a melhor oferta de compra } \\
\text { e o melhor preço de venda) tendem a recorrer ao valor justo para a } \\
\text { divulgação de PPI (Muller, Riedl \& Sellhorn, 2011). } \\
\text { - A variável assimetria informacional captura uma possível diferença } \\
\text { entre o julgamento realizado a partir da leitura das informações } \\
\text { contábeis feita pelos usuários internos (sobretudo gestores) e o } \\
\text { julgamento realizado pelo mercado acerca do valor justo das PPI (Pinto } \\
\text { et al., 2015). }\end{array}$ & $\begin{array}{l}\text { Espera-se que quanto maior a tendência de } \\
\text { os gestores optarem pelo tratamento contábil } \\
\text { que proporcione maior lucro, no caso deste } \\
\text { estudo, pelo valor justo, menor a assimetria } \\
\text { informacional (menor bid-ask spread) (sinal } \\
\text { negativo). } \\
\text { Variável explicativa utilizada: Bid-ask } \\
\text { spread apurados na última cotação do ano } \\
\text { (capturando o valor auferido pelo mercado na } \\
\text { última negociação do ano). }\end{array}$ \\
\hline $\begin{array}{l}\mathrm{H} 5 \text { : Empresas com maior } \\
\text { proporção de PPI com } \\
\text { relação ao ativo total são } \\
\text { mais propensas a adotar o } \\
\quad \text { valor justo. }\end{array}$ & $\begin{array}{c}\text {-Os gestores, em um cenário de assimetria informacional, farão a } \\
\text { opção pelo valor justo, para, assim, reduzir a assimetria e evidenciar o } \\
\text { valor da empresa, esperando que a escolha pelo valor justo para PPI } \\
\text { tenha relação com a proporção de PPI em relação ao ativo total da } \\
\text { empresa (Pereira, 2013). } \\
\text { - Ao testar a proporção de PPI com relação ao ativo total, identificou-se } \\
\text { que nas empresas brasileiras de exploração de imóveis que adotaram } \\
\text { o método do valor justo, mais de } 90 \% \text { dos ativos eram classificados } \\
\text { como PPI (Batista et al., 2013). }\end{array}$ & $\begin{array}{l}\text { Espera-se que a probabilidade de escolha do } \\
\text { valor justo aumente à medida que aumenta } \\
\text { a proporção de PPI em relação ao ativo total } \\
\qquad \text { (sinal positivo). } \\
\text { Variável explicativa utilizada: Quociente entre } \\
\quad \text { saldo de PPI e ativo total da empresa. }\end{array}$ \\
\hline $\begin{array}{l}\text { H6: Empresas auditadas } \\
\text { por Big Four são menos } \\
\text { propensas ao uso do valor } \\
\text { justo para PPI. }\end{array}$ & $\begin{array}{l}\text {-Empresas auditadas pelas maiores empresas de auditoria, } \\
\text { denominadas como Big Four (Deloitte, Ernst \& Young, KPMG e } \\
\text { Pricewaterhouse Coopers) estão menos associadas a práticas de } \\
\text { gerenciamento de resultados e costumam agir de forma mais } \\
\text { conservadora (Martinez, 2011; Lorencini \& Costa, 2012; Tsipouridou \& } \\
\text { Spathis, 2012). }\end{array}$ & $\begin{array}{l}\text { Espera-se que, se a empresa é auditada } \\
\text { por uma empresa de auditoria Big Four, } \\
\text { mais propensa é a adotar um método mais } \\
\text { conservador e menos propensa está em } \\
\text { adotar o valor justo (sinal positivo). } \\
\\
\text { Variável explicativa utilizada: A empresa } \\
\text { ser auditada ou não por uma empresa de } \\
\text { auditoria Big Four. }\end{array}$ \\
\hline $\begin{array}{l}\text { H7. O setor de atuação } \\
\text { impacta na escolha pelo } \\
\text { valor justo como método de } \\
\text { mensuração subsequente } \\
\text { para PPI. }\end{array}$ & $\begin{array}{l}\text {-O setor de atuação e o país de domicílio são fatores determinantes } \\
\text { para explicar as escolhas contábeis (Jaafar \& McLeay, 2007). } \\
\text {-O setor financeiro (bancos, seguradoras e setor imobiliário) é aquele } \\
\text { em que as empresas são mais dispostas a adotar o valor justo (Demaria } \\
\text { \& Dufour, 2007) }\end{array}$ & $\begin{array}{l}\text { Espera-se que o fato de pertencer a um } \\
\text { determinado setor (dummy setor) torne a } \\
\text { empresa mais propensa ao uso do valor justo } \\
\text { (sinal positivo). } \\
\text { Variável explicativa utilizada: setor de atuação } \\
\text { conforme classificação setorial referenciada } \\
\text { na listagem da NYSE, o ICB (Industry } \\
\text { Classification Benchmark), criado pela } \\
\text { Financial Times Stock Exchange International } \\
\text { Limited (FTSE) e Dow Jones \& Company. }\end{array}$ \\
\hline $\begin{array}{l}\text { H8. Empresas listadas na } \\
\text { NYSE são mais propensas ao } \\
\text { valor justo como método de } \\
\text { mensuração subsequente } \\
\text { para PPI. }\end{array}$ & $\begin{array}{c}\text {-O setor de atuação e o país de domicílio são fatores explicativos das } \\
\text { escolhas contábeis, porém as diferenças entre países são ainda maiores } \\
\text { do que entre setores (Jaafar \& McLeay, 2007). } \\
\text {-Quanto mais desenvolvido é o mercado de capitais no qual a empresa } \\
\text { é listada, maior será sua acessibilidade e aceitabilidade ao valor justo } \\
\text { (Pereira, 2013), além destas serem mais familiarizadas com o valor } \\
\text { justo, conforme considerado na IAS } 40 \text { (Basis for Conclusions, IAS 40, } \\
2013, \text { BC12). }\end{array}$ & $\begin{array}{l}\text { Espera-se que as empresas listadas na NYSE } \\
\text { optem pelo valor justo como método de } \\
\text { mensuração subsequente (sinal positivo). } \\
\text { Variável explicativa utilizada: } \\
\text { Bolsa de valores na qual a empresa está } \\
\text { listada (NYSE ou BM\&FBOVESPA). }\end{array}$ \\
\hline
\end{tabular}

Para identificar as características das entidades que podem levar a possíveis explicações para as escolhas contábeis dos gestores, empregou-se a técnica de regressão logística, que permite explicar e prever variáveis dicotômicas a partir da identificação de variáveis explicativas que sejam, estatisticamente, significativas (Fávero, Belfiore, Takamatsu \& Suzart, 2014). O método também tem sido comum em questões relacionadas às escolhas contábeis utilizando a abordagem metodológica empírico positivista (Demaria \& Dufour, 2007), bem como em pesquisas correlatas (Demaria \& Dufour, 2007; Jaafar \& McLeay, 2007, p. 157; Lorencini \& Costa, 2012; Andrade et al., 2013; Costa et al., 2013; Pereira, 2013; Taplin et al., 2014).

Por meio de testes usuais, foi identificado o modelo Probit como o melhor modelo para a base de dados da presente pesquisa, e de forma geral, a Equação 1 exprime o modelo testado. 
Desta forma, as variáveis testadas na identificação das características das empresas que se configuram como possíveis variáveis explicativas para as escolhas contábeis são resumidas no Quadro 4.

Quadro 4: Variáveis analisados no estudo

\begin{tabular}{|c|c|c|c|c|}
\hline Variável-Sigla & Hipótese & S.E & Métrica & Estudos motivadores \\
\hline Escolha Contábil - EC & & & Dummy: $0=$ custo; $1=$ valor justo & \\
\hline Rentabilidade-RENT & $\begin{array}{l}\text { H1: Empresas com alto nível de } \\
\text { rentabilidade (ROE) são mais } \\
\text { propensas ao uso do método do } \\
\text { valor justo para PPI }\end{array}$ & + & $\begin{array}{c}\text { Relação entre Lucro Operacional } \\
\text { Líquido (ajustado) e Patrimônio } \\
\text { Líquido Médio }\end{array}$ & $\begin{array}{c}\text { Andrade et al., 2013; } \\
\text { Christensen e Nikolaev, 2013; } \\
\text { Costa et al., 2013; Souza, } \\
\text { Botinha, Silva \& Lemes, } 2015\end{array}$ \\
\hline Endividamento-ENDIV & $\begin{array}{c}\text { H2: Empresas com maior grau } \\
\text { de endividamento são mais } \\
\text { propensas ao uso do método do } \\
\text { valor justo para PPI }\end{array}$ & + & $\begin{array}{c}\text { Total das dívidas/Patrimônio } \\
\text { Líquido }\end{array}$ & $\begin{array}{l}\text { Andrade et al., 2013; } \\
\text { Christensen e Nikolaev, 2013; } \\
\text { Costa et al., 2013; Taplin et al., } \\
\text { 2014; Souza et al. (2015) }\end{array}$ \\
\hline Tamanho-TAM & $\begin{array}{c}\text { H3: Empresas maiores são menos } \\
\text { propensas ao uso do valor justo } \\
\text { para PPI }\end{array}$ & - & Saldo do ativo total & $\begin{array}{l}\text { Demaria e Dufour, 2007; Costa } \\
\text { et al., 2013; Taplin et al., 2014; } \\
\text { Souza et al. (2015) }\end{array}$ \\
\hline $\begin{array}{l}\text { Assimetria Informacional- } \\
\text { ASSIM }\end{array}$ & $\begin{array}{l}\text { H4: Empresas com menores bid- } \\
\text { ask spread são mais propensas ao } \\
\text { uso do valor justo para PPI }\end{array}$ & - & $\begin{array}{l}\text { Diferença entre valor da oferta de } \\
\text { compra e valor da oferta de venda } \\
\text { da ação do último dia do ano. }\end{array}$ & $\begin{array}{c}\text { Muller et al., 2011; Martins et } \\
\text { al., } 2012\end{array}$ \\
\hline Proporção PPI-PROP & $\begin{array}{l}\text { H5: Empresas com maior } \\
\text { proporção de PPI com relação ao } \\
\text { ativo total são mais propensas a } \\
\text { adotar o valor justo }\end{array}$ & + & Relação entre PPI/Ativo Total & $\begin{array}{l}\text { Batista et al., 2013; Pereira, } \\
\text { 2013; Souza et al. (2015) }\end{array}$ \\
\hline Auditoria-BIGF & $\begin{array}{l}\text { H6: Empresas auditadas por Big } \\
\text { Four são menos propensas ao uso } \\
\text { do valor justo para PPI }\end{array}$ & - & $\begin{array}{c}\text { Dummy: } 0 \text { = auditada por não-Big } \\
\text { Four; } 1 \text { = auditada por Big Four }\end{array}$ & $\begin{array}{l}\text { Martinez, 2011; Tsipouridou } \\
\text { e Spathis, 2012; Souza et al. } \\
\text { (2015) }\end{array}$ \\
\hline Setor-SET & $\begin{array}{l}\text { H7: O setor de atuação impacta } \\
\text { na escolha pelo valor justo } \\
\text { como método de mensuração } \\
\text { subsequente para PPI }\end{array}$ & & $\begin{array}{c}\text { Dummy por setor: } 1=\text { Bens } \\
\text { de Consumo; } 2=\text { Financeiro; } \\
\text { 3=Industriais; } 4=\text { =Materiais Básicos; } \\
\text { 5=Serv. ao Consumidor; } 6= \\
\text { Telecom.; } 7=\text { Utilidades }\end{array}$ & $\begin{array}{c}\text { Jaafar e McLeay, 2007; Souza et } \\
\text { al. (2015) }\end{array}$ \\
\hline BOLSA & $\begin{array}{l}\text { H8: Empresas listadas na NYSE } \\
\text { são mais propensas ao uso } \\
\text { do valor justo como método } \\
\text { de mensuração subsequente } \\
\text { para PPI }\end{array}$ & & $\begin{array}{c}\text { Dummy: } 1=\text { empresa listada } \\
\text { na NYSE } 0=\text { empresa listada na } \\
\text { BM\&FBOVESPA }\end{array}$ & $\begin{array}{l}\text { Jaafar e McLeay, 2007; Pereira, } \\
\qquad 2013\end{array}$ \\
\hline
\end{tabular}

Legenda: S.E: Sinal esperado.

Conforme exposto no Quadro 4, a variável dependente do estudo é a variável Escolha Contábil, sendo que a opção do método de custo é a dummy 0 e a opção do método do valor justo é a dummy 1 .

\section{ANÁLISE DOS RESULTADOS}

\subsection{ANÁLISE DESCRITIVA DOS DADOS}

Nas Tabelas 1 e 2, é apresentada, respectivamente, a distribuição das frequências para as variáveis qualitativas e para as variáveis quantitativas.

Tabela 1: Estatística descritiva da distribuição de frequências das variáveis qualitativas

\begin{tabular}{|c|c|c|c|c|c|c|c|c|c|c|}
\hline & \multicolumn{2}{|c|}{ Geral } & \multicolumn{2}{|c|}{ EC - Custo } & \multicolumn{2}{|c|}{ EC - Valor Justo } & \multicolumn{2}{|c|}{ BM\&F } & \multicolumn{2}{|c|}{ NYSE } \\
\hline & $\begin{array}{l}\text { Freq. } \\
\mathrm{N}=95\end{array}$ & Freq. Rel.* & $\begin{array}{l}\text { Freq. } \\
\mathrm{N}=50\end{array}$ & Freq. Rel.* & $\begin{array}{l}\text { Freq. } \\
\mathrm{N}=45\end{array}$ & $\begin{array}{l}\text { Freq. } \\
\text { Rel.* }^{*}\end{array}$ & $\begin{array}{l}\text { Freq. } \\
\mathrm{N}=54\end{array}$ & Freq. Rel.* & $\begin{array}{l}\text { Freq. } \\
\mathrm{N}=41\end{array}$ & $\begin{array}{l}\text { Freq. } \\
\text { Rel.* }\end{array}$ \\
\hline \multicolumn{11}{|l|}{ EC - Escolha Contábil } \\
\hline 0 - Custo & 50 & $52,6 \%$ & - & - & - & - & 29 & $53,7 \%$ & 21 & $51,2 \%$ \\
\hline 1 - Valor justo & 45 & $47,4 \%$ & - & - & - & - & 25 & $46,3 \%$ & 20 & $48,8 \%$ \\
\hline \multicolumn{11}{|l|}{ Big Four } \\
\hline $\begin{array}{c}0 \text { - Não auditada por } \\
\text { Big Four }\end{array}$ & 14 & $14,7 \%$ & 4 & $8 \%$ & 10 & $22,2 \%$ & 11 & $20,4 \%$ & 3 & $7,3 \%$ \\
\hline $\begin{array}{c}1 \text { - Auditada por } \\
\text { Big Four }\end{array}$ & 74 & $77,9 \%$ & 42 & $84 \%$ & 32 & $71,1 \%$ & 36 & $66,7 \%$ & 38 & $92,7 \%$ \\
\hline ND & 7 & $7,4 \%$ & 4 & $8 \%$ & 3 & 6,7 & 7 & $12,9 \%$ & 0 & $0 \%$ \\
\hline \multicolumn{11}{|l|}{ Setor de atuação } \\
\hline 1 - Bens de Consumo & 11 & $11,6 \%$ & 6 & $12 \%$ & 5 & $11,1 \%$ & 6 & $11,1 \%$ & 5 & $12,2 \%$ \\
\hline
\end{tabular}




\begin{tabular}{|c|c|c|c|c|c|c|c|c|c|c|}
\hline 2- Financeiro & 46 & $48,4 \%$ & 21 & $42 \%$ & 25 & $55,6 \%$ & 23 & $42,6 \%$ & 23 & $56,1 \%$ \\
\hline 3 - Industriais & 11 & $11,6 \%$ & 5 & $10 \%$ & 6 & $13,3 \%$ & 9 & $16,7 \%$ & 2 & $4,9 \%$ \\
\hline 4 - Materiais Básicos & 7 & $7,4 \%$ & 3 & $6 \%$ & 4 & $8,9 \%$ & 4 & $7,4 \%$ & 3 & $7,3 \%$ \\
\hline $\begin{array}{c}5 \text { - Serviços ao } \\
\text { consumidor }\end{array}$ & 3 & $3,2 \%$ & 2 & $4 \%$ & 1 & $2,2 \%$ & 1 & $1,85 \%$ & 2 & $4,9 \%$ \\
\hline 6- Telecomunic'. & 5 & $5,2 \%$ & 4 & $8 \%$ & 1 & $2,2 \%$ & 1 & $1,85 \%$ & 4 & $9,8 \%$ \\
\hline 7- Utilidades & 5 & $5,2 \%$ & 5 & $10 \%$ & 0 & $0 \%$ & 3 & $5,6 \%$ & 2 & $4,8 \%$ \\
\hline ND & 7 & 7,4 & 4 & 8 & 3 & 6,7 & 7 & 12,9 & 0 & $0 \%$ \\
\hline Total & 95 & $100 \%$ & 50 & $100 \%$ & 45 & $100 \%$ & 54 & $100 \%$ & 41 & $100 \%$ \\
\hline
\end{tabular}

Legenda: *Frequência relativa estabelecida de forma vertical; BM\&F: BM\&FBOVESPA; ND: Dados empresa não disponível; NN: Não se aplica/Não divulga. 'Telecomunicaçōes.

Tabela 2: Estatística descritiva das variáveis quantitativas

\begin{tabular}{|c|c|c|c|c|c|c|}
\hline Variáveis/Bolsa & Obs & Média & Mediana & Desvio Padrão & Mínimo & Máximo \\
\hline \multicolumn{7}{|l|}{ GERAL } \\
\hline RENT(inv) & 84 & 0.261 & 0.101 & 0.821 & -1.484 & 5.051 \\
\hline RENT & 84 & 0.815 & 5.995 & 31.176 & -182.100 & 31.000 \\
\hline ENDIV & 88 & 2.765 & 0.767 & 14.964 & -8.053 & 139.509 \\
\hline TAM (In) & 88 & 9.673 & 8.867 & 2.729 & 4.954 & 15.658 \\
\hline TAM & 88 & 385981.10 & 7120.00 & 1055454.00 & 141.70 & 6309119.00 \\
\hline ASSIM (inv $\sqrt{ }$ ) & 78 & 5.645 & 5.000 & 3.343 & 0.141 & 18.257 \\
\hline ASSIM & 78 & 0.860 & 0.040 & 5.685 & 0.003 & 50.000 \\
\hline PROP(In) & 88 & -4.105 & -4.346 & 2.549 & -11.523 & -0.026 \\
\hline PROP & 88 & 0.154 & 0.013 & 0.276 & 0.000 & 0.975 \\
\hline \multicolumn{7}{|l|}{ BM\&FBOVESPA } \\
\hline RENT & 43 & -4.415 & 5.580 & 41.613 & -182.100 & 25.500 \\
\hline ENDIV & 47 & 3.603 & 0.653 & 20.444 & -8.053 & 139.509 \\
\hline TAM (In) & 47 & 7.833 & 8.047 & 1.417 & 4.954 & 10.261 \\
\hline TAM & 47 & 5930.06 & 3123.30 & 7794.12 & 141.70 & 28598.40 \\
\hline ASSIM (inv $\sqrt{ }$ ) & 37 & 0.383 & 4.082 & 1.045 & 0.010 & 6.000 \\
\hline ASSIM & 37 & 0.383 & 0.060 & 1.045 & 0.010 & 6.000 \\
\hline $\operatorname{PROP}(\sqrt{ })$ & 47 & 0.330 & 0.211 & 0.310 & 0.021 & 0.987 \\
\hline PROP & 47 & 0.203 & 0.045 & 0.293 & 0.000 & 0.975 \\
\hline \multicolumn{7}{|l|}{ NYSE } \\
\hline RENT & 41 & 6.299 & 6.870 & 11.764 & -49.200 & 31.000 \\
\hline $\operatorname{ENDIV}(\sqrt{ })$ & 41 & 1.184 & 0.976 & 0.643 & 0.073 & 3.285 \\
\hline ENDIV & 41 & 1.804 & 0.952 & 2.144 & 0.005 & 10.789 \\
\hline TAM (In) & 41 & 11.783 & 11.664 & 2.313 & 7.918 & 15.658 \\
\hline TAM & 41 & 821649.30 & 116301.90 & 1434775.00 & 2745.10 & 6309119.00 \\
\hline ASSIM (inv $\sqrt{ }$ ) & 41 & 7.063 & 7.071 & 3.491 & 0.141 & 18.257 \\
\hline ASSIM & 41 & 1.290 & 0.020 & 7.799 & 0.003 & 50.000 \\
\hline PROP(In) & 41 & -4.959 & -5.178 & 2.492 & -11.523 & -0.040 \\
\hline PROP & 41 & 0.098 & 0.006 & 0.246 & 0.000 & 0.961 \\
\hline
\end{tabular}

Legenda: TAM (In) - variável tamanho da empresa medido pelo logaritmo natural do saldo do ativo; PROP(In) - variável proporção do saldo de PPI em relação ao ativo total corrigido os desvios por meio do logaritmo natural da proporção; $\operatorname{PROP}(\sqrt{ })$ - variável proporção do saldo de PPI em relação ao ativo total corrigido os desvios por meio da aplicação de raíz quadrada; RENT(inv) - variável rentabilidade medida pelo ROE e corrigido pela aplicação daa inversão (1/rent); ENDIV( $\sqrt{ }$ ) $\sqrt{ })$ - variável de assimetria informacional medida pela diferença entre o preço de compra (BID) e o preço de venda (ASK) da ação corrigido pelo inverso do saldo multiplicado pela raíz quadrada.

Para uma análise mais encadeada, os dados da Tabela 1 e da Tabela 2 serão discutidos juntamente à análise dos dados obtidos por meio da aplicação da regressão logística, para identificar a influência dos incentivos das empresas na escolha contábil.

Vale destacar alguns pontos complementares, necessários ao entendimento da Tabela 2. Primeiramente, é importante esclarecer que são apresentados tantos os valores das variáveis com saldo bruto coletado, quanto os valores corrigidos a partir do método de correção indicado pelo resultado 
da aplicação da técnica Kernel density estimate, que visa suavizar os dados que não permitiram que a curva dos dados se apresentasse como normal.

Outro ponto é que, para identificar se de fato as frequências observadas são semelhantes às esperadas, foi aplicado o teste de Qui-Quadrado e o teste de correlação, visando identificar se, a partir de combinações feitas, as variáveis qualitativas e quantitativas revelam ausência de correlação. Para as variáveis quantitativas, nenhuma das associações apresentou grau de correlação de magnitude alta ou muito forte.

Para as variáveis qualitativas, o teste de Qui-Quadrado apontou que as variáveis Big Four e Bolsa evidenciam uma associação significativa entre elas. Em busca de um modelo que fornecesse maior poder explicativo para as escolhas, foi testado qual das duas variáveis inseridas no modelo revelaria, estatisticamente, maior poder explicativo para a escolha contábil, que, neste caso, foi a variável Big Four, sendo, portanto, a variável Bolsa omitida do modelo. O baixo poder explicativo da variável Bolsa pode se dar em face dos números referentes às escolhas contábeis serem muito próximos entre os mercados (46,8\% das empresas listadas na BM\&FBovespa e 48,8\% das listadas na NYSE adotaram o valor justo).

De um modo geral, verificou-se que as empresas listadas em ambas as bolsas optaram, em maior grau, pela mensuração subsequente ao custo em detrimento da adoção do valor justo. Esses resultados podem fornecer indícios de que as empresas ainda mantêm o método anterior de mensuração, uma indicação da manutenção do status quo.

Na pesquisa de Pinto et al. (2015), questionados os analistas sobre a presença de status quo em suas escolhas na mensuração de PPI, estes a negaram, alegando que esse comportamento apenas seria dotado de sentido se a norma permitisse não mensurar as PPI ao valor justo. No entanto, se adotado o uso do custo histórico, o valor justo deve ser divulgado em notas explicativas, ou seja, na visão dos analistas entrevistados, não haveria redução do trabalho, não sendo possível optar por manter um método de mensuração anterior por uma questão de comodismo, conforme fundamenta o status quo. Os analistas sugerem, ainda, que as empresas que não optaram pelo valor justo podem ter feito essa opção por uma perspectiva de futuro aumento nas taxas de juros que afetaria o valor de seus ativos. Entretanto, na presente pesquisa, objetiva-se destacar o comportamento conservador e a existência do status quo, mas instigam-se maiores investigações por meio de pesquisas futuras para confirmar tal hipótese, já que existem autores que não concordam com essa teoria.

Outro ponto a ser considerado é o fato de não se ter identificado, na pesquisa, que empresas listadas em um mercado de capitais mais desenvolvido (NYSE) resultaria em maior aceitabilidade ao valor justo ou maior familiarização e experiência com o método, conforme levantado na seção do referencial teórico (Basis for Conclusions, IAS 40, 2013, BC12; PEREIRA, 2013). Tal percepção se deu a partir dos percentuais de adoção do valor justo terem sido próximos (46,8\% das empresas da BM\&FBovespa e 48,8\% das listadas da NYSE) e da variável Bolsa ter sido excluída do modelo a partir de testes estatísticos.

Quanto à adoção do valor justo, preferencialmente pelo setor financeiro (Demaria \& Dufour, 2007), verificou-se que, das entidades que mensuraram as PPI ao valor justo, 55,6\% pertencem ao setor financeiro e destas 54,3\% adotam o valor justo, ao passo que das empresas que não pertencem ao setor financeiro, 59,2\% adotaram o método do custo. No entanto, não foi identificada significância estatística para o setor financeiro.

Outro ponto analisado, descritivamente, foi o disclosure contábil referente à PPI. Conforme apresentado na IAS 40, se a empresa opta pelo método do custo, esta deve divulgar o respectivo valor justo em notas explicativas. Ou seja, para as empresas que não optaram pelo valor justo, torna-se fundamental a sua divulgação, sendo necessária, nesta, a mensuração e evidenciação das PPI ao valor justo. 
Verificou-se que, das empresas optantes pelo método do custo, 68\% (34 empresas do total de 50 ) divulgaram o valor justo. Na análise por mercado de capitais, do total de empresas listadas na BM\&FBOVESPA, 55\% (16 empresas de 29 no total) divulgaram o método do valor justo quando feita a opção do reconhecimento posterior das PPI ao valor de custo, enquanto $45 \%$ das empresas não fizeram a devida divulgação. Um cenário bastante diferente ocorre para as empresas listadas na NYSE, que apresenta $86 \%$ das empresas (18 de 21 empresas) divulgando o valor justo das PPI, quando optaram pelo reconhecimento do item com base no valor de custo.

Andrade et al. (2013), em análise semelhante, identificaram que 35\% das empresas da amostra (constituída por empresas listadas também na BM\&FBOVESPA) que mensuraram as PPI ao método do custo, não divulgaram o saldo da conta ao valor justo. Pode-se inferir que, no que se refere ao disclosure contábil, as empresas listadas em um mercado mais desenvolvido parecem apresentar maior disposição (ou enforcement) em divulgar os saldos a valor justo.

\subsection{INFLUÊNCIA DAS CARACTERÍSTICAS DAS EMPRESAS NA ESCOLHA CONTÁBIL}

Anterior à elaboração e aplicação da regressão logística múltipla, aplicou-se a estimação de stepwise, identificando-se a variável rentabilidade como não contribuindo significativamente como uma variável discriminatória. Assim, não foram inseridas as variáveis ROE e bolsa no modelo. Os resultados da estimação dos efeitos marginais, por meio do modelo geral Probit, são apontados na Tabela 3.

Tabela 3: Resultados dos efeitos marginais para o modelo Probit

\begin{tabular}{|c|c|c|c|c|c|c|c|c|}
\hline Variável & Efeitos Marginais & Desvio Padrão & Z & $P>z$ & \multicolumn{2}{|c|}{ [95\% Inter. de Confiança] } & $\mathrm{H}$. & Sinal \\
\hline \multicolumn{9}{|l|}{ Setor } \\
\hline 2 & 0.041946 & 0.143957 & 0.29 & 0.771 & -0.240205 & 0.324097 & $\mathrm{H} 7$ & n.s. \\
\hline 3 & 0.143990 & 0.182999 & 0.79 & 0.431 & -0.214681 & 0.502660 & $\mathrm{H} 7$ & n.s. \\
\hline 4 & 0.290520 & 0.197381 & 1.47 & 0.141 & -0.096339 & 0.677379 & $\mathrm{H} 7$ & n.s. \\
\hline 5 & 0.217517 & 0.284555 & 0.76 & 0.445 & -0.340199 & 0.775234 & $\mathrm{H} 7$ & n.s. \\
\hline 6 & -0.298653 & 0.148189 & -2.02 & 0.044 & -0.589098 & -0.008207 & $\mathrm{H} 7$ & + \\
\hline 7 & (não estimado)* & & & & & & $\mathrm{H} 7$ & n.s. \\
\hline ENDIV & -0.017394 & 0.023339 & -0.75 & 0.456 & -0.063137 & 0.028350 & $\mathrm{H} 2$ & n.s. \\
\hline $\operatorname{TAM}(\ln )$ & 0.072763 & 0.027440 & 2.65 & 0.008 & 0.018983 & 0.126544 & $\mathrm{H} 3$ & + \\
\hline ASSIM & 0.028399 & 0.015764 & 1.80 & 0.072 & -0.002498 & 0.059295 & $\mathrm{H} 4$ & n.s. \\
\hline PROP(In) & 0.065384 & 0.020661 & 3.16 & 0.002 & 0.024890 & 0.105878 & $\mathrm{H} 5$ & + \\
\hline BIGF & -0.535926 & 0.146225 & -3.67 & 0.000 & -0.822522 & -0.249330 & $\mathrm{H} 6$ & - \\
\hline Prob > chi2 & $=$ & 0.0058 & & \multicolumn{3}{|c|}{ Sensibilidade $=72.22 \%$} & & \\
\hline Pseudo R2 & $=$ & 0.2242 & & \multicolumn{3}{|c|}{ Especificidade $=75.68 \%$} & & \\
\hline \multicolumn{2}{|c|}{ Hosmer-Lemeshow $\left(\right.$ Prob $\left.>c^{2} i^{2}\right)=$} & \multicolumn{2}{|c|}{0.2052} & \multicolumn{3}{|c|}{ Class corret $=73.97 \%$} & & \\
\hline Cox \& Snell $\left(R^{2}\right)$ & $=$ & \multicolumn{2}{|l|}{0.2670} & \multicolumn{3}{|c|}{ Curva ROC $=0.8071$} & & \\
\hline Nagelkerke $\left(R^{2}\right)$ & $=$ & \multicolumn{2}{|l|}{0.3560} & & & & & \\
\hline
\end{tabular}

Legenda: *Efeitos marginais não estimados devidos a todas as empresas do setor (após a exclusão das empresas que não haviam dados disponíveis no sistema de coleta de dados) terem adotado o mesmo método.

Constatou-se, por meio dos resultados apresentados, que o modelo é adequado, uma vez que possui probabilidade de qui-quadrado de 0,0058 (pseudo $r^{2}$ de 0,2242). Diante desses resultados, verifica-se que as hipóteses $\mathrm{H} 1, \mathrm{H} 2, \mathrm{H} 4$ e H8 não foram aceitas, pois se apresentaram estatisticamente não significativas para o modelo.

Dentre as variáveis que apresentaram significância estatística, a variável que possui maior influência significativa na escolha contábil é o fato de a empresa ser auditada por uma Big Four (H6), com coefi- 
ciente de significância igual a 0 , validando a hipótese de monitoramento, ao apresentar que o fato de a empresa ser auditada por uma das Big Four reduz em cerca de $54 \%$ a probabilidade de a empresa mensurar seus PPI ao valor justo.

O resultado ainda valida o observado na estatística descritiva, em que $77,9 \%$ das empresas foram auditadas por Big Four no ano de 2013, e destas, a maioria (56,76\%) optou pela mensuração ao custo. Um fato a ser destacado é que, apesar de as empresas da NYSE apresentarem um grau de adesão maior ao valor justo (48,8\%), a maior parte delas é auditada por Big Four. Esse resultado corrobora outros estudos que também identificaram a influência do fato de a empresa ser auditada por uma Big Four para a escolha contábil pelo método mais conservador (Lorencini \& Costa, 2012; Souza et al., 2015).

Outra variável significativa foi a relevância do saldo da conta de PPI sobre os ativos totais, aceitando-se a hipótese H5, convalidando pesquisas anteriores (Pereira, 2013; Souza et al., 2015), que encontraram que quanto maior os valores das PPI em relação ao ativo total, maiores são os incentivos para mensurar as PPI ao valor justo. Ressalta-se, no que diz respeito a essa variável (conforme Tabela 2), que, apesar de, em média, o volume de ativos das empresas listadas na NYSE ser maior do que o das listadas na BM\&FBOVESPA, a proporção de PPI em relação ao saldo de ativo total das empresas listadas na BM\&FBOVESPA $(0,20)$ mostrou-se em proporção maior do que a registrada pelas empresas listadas na NYSE $(0,10)$. Infere-se que este fato seja em decorrência da amostra de empresas listadas na BM\&FBOVESPA conter uma grande representatividade de empresas atuantes no setor imobiliário $(81,0 \%)$.

Cabe destacar que a análise da escolha do método contábil, no que se refere à proporção de PPI em relação aos ativos totais, pode apresentar um viés pelo fato de o próprio PPI mensurado ao valor justo aumentar os ativos totais da empresa, sendo uma alternativa ao problema utilizar a variável ativo total sem o efeito das PPI. Porém, foi utilizada a fórmula apresentada por ter sido validada em estudos anteriores.

Observa-se que, para a dummy setor, apenas o setor de telecomunicações (Setor 6, com p-value de 0,044) expôs significância estatística, porém com sinal negativo, ou seja, o fato de pertencer ao setor de telecomunicações reduz a probabilidade de a empresa aderir ao valor justo, corroborando o estudo de Souza et al. (2015). Esse resultado é suficiente para rejeitar a hipótese $H 7$, que assegura que o setor de atuação pode impactar na escolha pelo valor justo como método de mensuração subsequente para PPI.

Os resultados dos efeitos marginais apontam que o fato de a empresa pertencer ao setor de telecomunicações reduz em cerca de $30 \%$ as chances de que esta opte pelo método do valor justo. Embora não tenha sido encontrada, na literatura e normas específicas do setor, explicação para este fato, pode haver para esse setor em específico certo conservadorismo na opção pelo valor justo.

O resultado referente à rentabilidade $(\mathrm{H} 1)$ confirma as constatações de estudos anteriores que não identificaram significância estatística para a variável rentabilidade, podendo inferir que ela tende a não explicar as escolhas contábeis referentes à mensuração subsequente para PPI (Andrade et al., 2013; Christensen \& Nikolaev, 2013; Costa et al., 2013; Pereira, 2013; Souza et al., 2015). Se os gestores tomam suas decisões livres de vieses quanto a prêmios de rentabilidade, ou seja, sem o plano de incentivo, tal prática pode gerar menores problemas relacionados ao gerenciamento de resultados.

Assim como para o grau de rentabilidade, a pesquisa corrobora estudos anteriores, os quais identificaram uma baixa sensibilidade das escolhas contábeis perante as proxies de endividamento, apresentando não significância estatística (Demaria \& Dufour, 2007; Andrade et al., 2013; Costa et al., 2013; Souza et al., 2015; Taplin et al., 2014), não sendo aceita, portanto, a hipótese do grau de endividamento (H2).

O apontamento da significância estatística da variável endividamento pode convalidar o apontamento feito por um dos entrevistados de empresas do setor de exploração de imóveis na pesquisa de Pinto et al. (2015), na qual se afirmou não acreditar no uso do valor justo para cumprir cláusulas restritivas 
em empréstimos por entender ser uma prática arriscada, uma vez que, em momentos de mudança na economia, a variação do valor justo poderia ser negativa, sendo necessário renegociar as dívidas. Embora o mesmo entrevistado declare não descartar a possibilidade existente de o valor justo proporcionar aumento no valor do patrimônio líquido e, consequentemente, permitir o aumento das dívidas.

Ao contrário do que se esperava, pelos constructos das hipóteses levantadas inicialmente, verifica-se que quanto maior o tamanho da empresa, maiores são as chances de sua opção pelo valor justo, indo em direção oposta aos resultados encontrados em pesquisas anteriores (Costa et al., 2013; Pereira, 2013; Taplin et al., 2014), e rejeitando a hipótese H3. Esperava-se que, partindo da hipótese dos custos políticos, a empresa, visando reduzir os "holofotes" sobre ela, adotasse um comportamento conservador (método do custo) como inferido nas pesquisas anteriormente mencionadas, o que não ocorreu.

Como possíveis inferências, esse comportamento não conservador pode ter sido motivado por uma relação de custo-benefício, uma vez que os benefícios de se aumentar o resultado (como, por exemplo, em apresentar uma informação mais realista e prospectiva aos usuários) podem ter sido superiores aos riscos de estar em evidência. Desse modo, o próprio custo de divulgação da informação já seria uma possível explicação para a relação encontrada.

Com relação à assimetria da informação, foram encontrados resultados diferentes das pesquisas de Muller et al. (2011) e de Martins et al. (2012), nas quais foram identificados significância estatística na relação entre a opção pelo valor justo e o nível de assimetria informacional, apontando, conforme Pinto et al. (2015), que o valor justo das PPI capitalizadas pelas empresas que o adotam seria próximo do valor que o próprio mercado estabelece para esses ativos. Esperava-se comportamento similar, o que não foi encontrado. A Figura 1 resume os resultados encontrados na pesquisa.

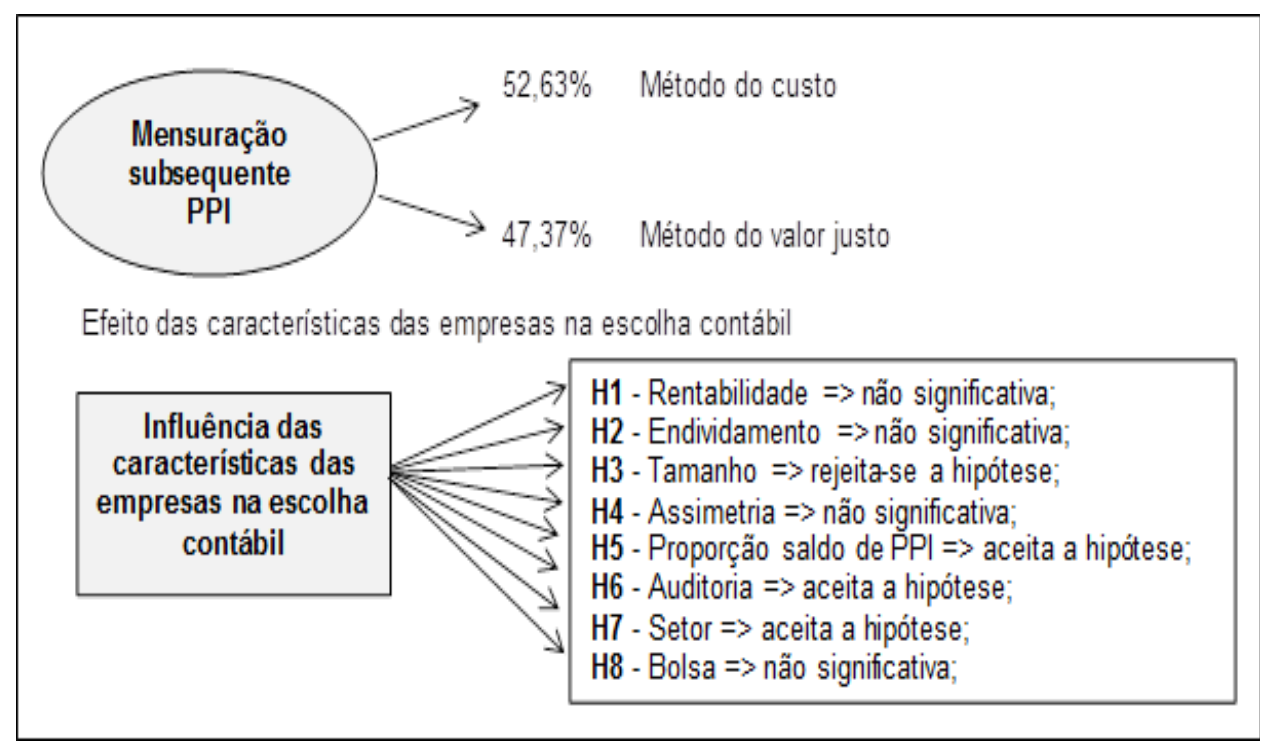

Figura 1: Resumo dos resultados.

No que se refere à confiabilidade do modelo e de seu poder explicativo, o teste de Hosmer-Lemeshow (prob $>\mathrm{chi}^{2}$ de 0,2052 ) revelou que o modelo está adequado e possui um bom ajuste, sendo confirmado pelo teste de Cox \& Snell juntamente ao teste de Nagelkerke, que indicaram que o modelo é capaz de explicar as variações ocorridas nas variáveis utilizadas.

Para julgar a acurácia do modelo, no que tange à respectiva classificação geral, diante da Curva ROC (Receiver Operating Characteristic), tem-se que o modelo classificou corretamente $80,71 \%$ do que foi analisado, permitindo-se interpretar, baseado no estudo de Hosmer e Lemeshow (2000), que o modelo 
apresenta um poder discriminatório excelente. Tais testes estatísticos mostram que os resultados obtidos permitem que as inferências sejam realizadas.

\section{CONSIDERAÇÕES FINAIS}

A presente pesquisa teve como objetivo identificar os possíveis incentivos para as escolhas contábeis realizadas pelos gestores de companhias abertas listadas na NYSE e na BM\&FBOVESPA, com relação à mensuração subsequente de PPI. As discussões e hipóteses da pesquisa acerca dos incentivos foram embasadas na Teoria da Agência e na abordagem metodológica empírico positivista, assumindo, como pressuposto, que as escolhas contábeis possam ser explicadas por meio da relação entre as características das empresas e os interesses dos gestores, cumprindo à pesquisa contábil, sob a óptica da abordagem teórica utilizada e por meio da identificação dos incentivos, explicar e predizer as práticas contábeis.

A análise sobre o item PPI permitiu discutir dois conceitos inseridos no Brasil por meio das IFRS e, frequentemente, criticados: a flexibilidade permitida nas normas por meio das escolhas e a inserção do método de mensuração do valor justo. Um dos pontos motivadores da pesquisa foi buscar compreender as decisões contábeis são, usualmente, tomadas com base em interesses pessoais dos gestores, e se existem características das empresas que contribuem para predizer as escolhas contábeis, não sendo tais escolhas apenas frutos do acaso.

Outro ponto motivador da pesquisa foi a controvérsia do tema, pois, de um lado, estão os objetivos das normas com um escopo que idealiza o uso do julgamento profissional por meio das escolhas contábeis, a fim de representar fielmente a substância econômica dos eventos e alcançar a comparabilidade das demonstrações contábeis. De outro lado, a existência nas normas de um número considerável de opções de práticas contábeis pode se distanciar deste objetivo à medida que as escolhas possam ser direcionadas por outras motivações, distanciando-se, consequentemente, da comparabilidade.

Controvérsia também pode ser encontrada por meio dos resultados de pesquisas anteriores, em que, observando, de um lado, pesquisas mostrando que o método de mensuração subsequente ao valor justo para PPI está sendo adotado por muitas empresas e, de outro, pesquisas apontando o método do custo histórico como sendo ainda o método mais utilizado.

Esperava-se encontrar, na presente pesquisa, uma adesão quase generalizada na escolha pelo método de mensuração subsequente do PPI ao valor justo por dois motivos: (i) por identificar certa preferência dos órgãos reguladores pela adesão ao valor justo (como retratado na seção 2.1); e (ii) por ser um item com menor complexidade na identificação do valor justo que outros itens patrimoniais, em função da existência de um mercado ativo. Esperava-se, ainda, que essa adesão ocorresse em proporções consideravelmente maiores para as empresas listadas na NYSE, como mercado de capitais desenvolvido, do que para as listadas na BM\&FBOVESPA.

Ao contrário do que se esperava, a presente pesquisa identificou que, de uma forma mais conservadora, para ambas as bolsas, ocorreu maior utilização do método do custo. Esperava-se, também, que o modelo confirmaria muitas das hipóteses de incentivos levantadas na plataforma teórica; entretanto, apenas algumas delas se confirmaram.

O modelo testado para a identificação da influência das características das empresas na escolha contábil, independente da bolsa de listagem, apontou significância estatística para as seguintes variáveis: a empresa ser auditada por uma Big Four, tamanho da empresa, relevância do saldo de PPI e a empresa pertencer ao setor de telecomunicações, isto é, o fato de a empresa não ser auditada por uma Big Four, pertencer ao setor de telecomunicações e apresentar proporções maiores de ativo total e de saldo de PPI, aumenta as chances de a empresa adotar o método do valor justo. Observou-se, 


\section{REFERÊNCIAS}

Andrade, M.E.M.C., Silva, D.M., \& Malaquias, R.F. (2013). Escolhas Contábeis em Propriedades para Investimento. Revista Universo Contábil, 9(3), 22-37.

Barth, M. (2008). Global Financial Reporting: Implications for U.S. Academics. The Accounting Review, 83(5), 1159-1179.

Batista, F.F., Prado, A.G.S., Machado, M.R., \& Paulo, E. (2013, jan.-jun.). Uma análise da mensuração e evidenciação de propriedades para investimento nas companhias brasileiras do setor de exploração de imóveis. Revista Ambiente Contábil, UFRN, Natal-RN, 5(1), 281-299.

Bayerlein, L., \& AI Farooque, O. (2012). Influence of a mandatory IFRS adoption on accounting practice: Evidence from Australia, Hong Kong and the United Kingdom. Asian Review of Accounting, 20(2), 93-118.

Cairns, D., Massoudi, D., Taplin, R., \&Tarca, A. (2011). IFRS fair value measurement and accounting policy choice in the United Kingdom and Australia. The British Accounting Review, 43, 1-21.

Carmona, S., \& Trombetta, M. (2008). On the global acceptance of IAS/IFRS accounting standards: The logic and implications of the principles-based system. Journal Accounting Public Policy, 27, 455-461.

Carvalho, L.N., Lemes, S., \& Costa, F.M.da. (2006). Contabilidade Internacional: aplicação das IFRS 2005. São Paulo: Atlas.

Christensen, H.B., \& Nikolaev, V.V. (2013). Does fair value accounting for non-financial assets pass the market test? Review of Accounting Studies, 18, 734-775.

Cole, V., Branson, J., \& Breesch, D. (2011). Determinants influencing the De facto Comparability of European IFRS Financial Statements. Recuperado em 15 dezembro, 2013, de http://papers.ssrn.com/sol3/papers.cfm?abstract_id=1967001

Costa, T.A., Silva, A.H.C., \& Laurencel, L.C. (2013). Escolha de práticas contábeis: um estudo sobre propriedades para investimento em empresas brasileiras não financeiras de capital aberto. Revista de Contabilidade e Organizações, 18, 25-36.

DeAngelo, H., DeAngelo, L., \& Skinner, D.J. (1994). Accounting choice in troubled companies. Journal of Accounting and Economics, 17, 113-143.

Demaria, S., \& Dufour, D. (2007). First time adoption of IFRS, Fair value option, Conservatism: Evidences from French listed companies. Recuperado em 26 dezembro, 2013, de http://hal.archives-cuvertes.fr/docs/00/26/61/89/PDF/ First_adoption_and_fair_value_Demaria_Dufour.pdf

Fávero, L.P., Belfiore, P., Takamatsu, R.T., \& Suzart, J. (2014). Métodos Quantitativos com Stata. Rio de Janeiro: Elsevier.

Fields, T.D., Lys, T.Z., \& Vincent, L. (2001). Empirical research on accounting choice. Journal of Accounting and Economics, 31, 255-307.

Framework (2013). The Conceptual Framework for Financial Reporting. Disponível em: $<$ http://www.ifrs.org $>$. Acesso em: 28-dez.2013.

Freri, M.R., \& Salotti, B.M. (2013, jan.-abr.). Comparabilidade de empresas administradoras de shoppings centers do mercado de capitais brasileiro. Revista de Contabilidade do Mestrado em Ciências Contábeis da UERJ (online), Rio de Janeiro, $18(1), 26-45$.

Hosmer, D.W., \& Lemeshow, S. (2000). Applied Logistic Regression, 2a ed., New York: John Wiley \& Sons.

International Financial Reporting Foundation. (2013). International Accounting Standards Board: Property, plant and equipment, IAS 40 .

International Financial Reporting Foundation. (2014) Jurisdiction Profiles. Recuperado em 20 abril, 2014, de http://www. ifrs.org/Use-around-the-world/Pages/Jurisdiction-profiles.aspx

Jaafar, A., \& McLeay, S. (2007). Country Effects and Sector Effects on the Harmonization of Accounting Policy Choice. ABACUS, 43(2), 156-189.

Jensen, M.C., \& Meckling, W.H. (1976). Theory of the firm: managerial behavior, agency costs and ownership structure. Journal of Financial Economics, 3, 305-360. 
Lopes, A.B. (2012). A teoria dos contratos, governança corporativa e contabilidade. In: A. B. Lopes, \& S. de ludícibus (coord.). Teoria Avançada de Contabilidade (2a ed). São Paulo: Atlas.

Lorencini, F.D., \& Costa, F.M.da. (2012, jan.-abr.). Escolhas contábeis no Brasil: identificação das características das companhias que optaram pela manutenção versus baixa dos saldos do ativo diferido. Revista de Contabilidade \& Finanças, USP, São Paulo, 23(58), 52-64.

Lourenço, I.C., \& Curto, J.D. (2010). Determinants of the Accounting Choice between Alternative Reporting Methods for Interests in Jointly Controlled Entities. European Accounting Review, 35.

Martinez, A.L. (2011, out.-dez.). Do corporate governance special listing segments and auditing curb real and accrual-based earnings management? Evidence from Brazil. Revista Universo Contábil, Blumenau, 7(4), 98-117.

Martins, E., Gelbcke, E.R., Santos, A. dos, \& ludícibus, S.de. (2013). Manual de Contabilidade Societária: aplicável a todas as sociedades de acordo com as normas internacionais e do CPC (2a ed.). São Paulo: Atlas.

Martins, V.A., Pinto, M.J.T., \& Alcoforado, E. (2012). Escolhas contábeis na mensuração de propriedades para investimento das empresas brasileiras de capital aberto. Congresso Nacional de Administração e Ciências Contábeis - AdCont, Rio de Janeiro, Brasil, 3.

Messier, W.F. Jr., Quick, L.A., \& Vandervelde, S.D. (2014). The influence of process accountability and accounting standard type on auditor usage of a status quo heuristic. Accounting, Organizations and Society, 39, 59-74.

Muller, K.A., Riedl, E.J., \& Sellhorn, T. (2008). Causes and Consequences of Choosing Historical Cost versus Fair Value. Recuperado em 26 dezembro, 2013, de http://nd.edu/ carecob/May2008Conference/Papers/RiedIMRS03062008.pdf

Muller, K.A., Riedl, E.J., \& Sellhorn, T. (2011). Mandatory Fair Value Accounting and Information Asymmetry: Evidence from the European Real Estate Industry. Recuperado em 26 dezembro, 2013, de http://ssrn.com/abstract=1244662

Pereira, A.F. (2013). Determinantes na escolha do valor justo para Propriedades para Investimentos no Brasil. Dissertação de Mestrado não-publicada, Faculdade de Economia, Administração e Contabilidade, Universidade de São Paulo, São Paulo, SP, Brasil.

Pinto, M.J.T., Martins, V.A., \& Silva, D.M. (2015, set.-dez.). Escolhas Contábeis: o Caso Brasileiro das Propriedades para Investimento. Revista Contabilidade \& Finanças, USP, 26(69), 274-289.

Roberts, C.B., Salter, S.B., \& Kantor, J. (1996). The IASC Comparability Project: A Cross-National Comparison of Financial Reporting Practices and IASC Proposed Rules. Journal of International Accounting \& Taxation, 5(1), 89-111.

Souza, F.E.A., Botinha, R.A., Silva, P.R., \& Lemes, S. (2015, mai.-ago.). A comparabilidade das escolhas contábeis na avaliação posterior de propriedades para investimento: uma análise das companhias abertas brasileiras e portuguesas. Revista de Contabilidade \& Finanças da USP, São Paulo, 26(68), 154-166.

Taplin, R., Yuan, W., \& Brown, A. (2014). The use of fair value and historical cost accounting for investment properties in china. Australasian Accounting, Business and Finance Journal, 8(1), 101-113.

Thorell, P., \& Whittington, G. (1994). The harmonization of accounting within the EU: problems, perspectives and strategies. The European Accounting Review, 3(2), 215-239.

Tonetto, L. M., Kalil, L.L., Melo, W.V., Schneider, D.D.G., \& Stein, L.M. (2006, abr.-jun.). O papel das heurísticas no julgamento e na tomada de decisão sob incerteza. Estudos de Psicologia, Campinas, 23(2), 181-189.

Tsipouridou, M., \& Spathis, C. (2012). Earnings management and the role of auditors in an unusual IFRS context: The case of Greece. Journal of International Accounting, Auditing and Taxation, 21, 62-78.

Tudor, A.T., Dragu, I.M. (2010). Impact of International Financial Reporting Standards on Accounting Practices Harmonization within European Union - Particular Case of Intangible Assets. Annales Universitatis Apulensis Series Oeconomica, 12(1), 191-206.

Watts, R.L. (1992). Accounting choice theory and market-based research in accounting. British Accounting Review, 24, 235-267.

Watts, R.L., \& Zimmerman, J.L. (1986). Positive accounting theory. Upper Saddle River: Prentice Hall.

World Federation of Exchanges. (2013). WFE Market Highlights. Recuperado em 25 maio, 2014, de http://www.world-exchanges.org/files/2013_WFE_Market_Highlights.pdf 